Research Article

\title{
Dynamic System Analysis of Leadership Effectiveness in Complex Environments
}

\author{
Shubing Guo, ${ }^{1}$ Yaming Hou, ${ }^{1}$ Hui Jiang $\mathbb{D}^{1},{ }^{1}$ Xueli Zhan $\mathbb{D}^{1,2}$ and Junhai Ma ${ }^{1}$ \\ ${ }^{1}$ College of Management and Economics, Tianjin University, Tianjin 300072, China \\ ${ }^{2}$ School of Economics, Beijing Wuzi University, Beijing 101149, China \\ Correspondence should be addressed to Hui Jiang; huijiang369@163.com and Xueli Zhan; xuelz20163205@126.com
}

Received 26 September 2020; Revised 10 December 2020; Accepted 10 February 2021; Published 8 March 2021

Academic Editor: Fabio Tramontana

Copyright (C) 2021 Shubing Guo et al. This is an open access article distributed under the Creative Commons Attribution License, which permits unrestricted use, distribution, and reproduction in any medium, provided the original work is properly cited.

In this paper, based on chaos theory and dynamic system simulation, a dynamic model of a relational leadership system with pressure factors is established and simulated. The study found that the excessive self-leadership and the relational leadership cannot effectively improve the leadership effectiveness of leaders. In addition, with the adjustment of the self-leadership adjustment coefficient, leadership effectiveness will change from a stable state to a chaotic state. Only by adopting limited rational decision-making strategies in multicycle decision-making can leaders maintain a high level of leadership effectiveness. Previous research mainly focuses on the theoretical analysis of the complexity of the leadership system or the issuance of questionnaires, but seldom on the dynamic complex process of the leadership system. This study reveals the complexity and chaos characteristics of the dynamic evolution of the multifactor relational leadership system, puts forward the relational leadership theory and the complex leadership theory under the influence of pressure, and makes some suggestions on how to improve the leadership effectiveness under the complex environment. The research results are of great significance to theoretical innovation and practical application.

\section{Introduction}

Leadership reflects a person's ability to make full use of surrounding resources to solve problems at the minimum cost and improve the efficiency of the whole team in a specific environment. The level of leadership often has a direct impact on an enterprise's internal cultural environment and the future strategic development policy. An excellent leader can always make the most appropriate decision at the most appropriate time to maximize his leadership effectiveness. However, with the continuous update of science and technology and the deepening of global integration, the environment of leaders is constantly changing and the challenges they face are increasingly severe. Therefore, leaders not only need to have a more comprehensive understanding of the components of leadership but also need to further improve their leadership on this basis. Therefore, the study of leadership becomes very important.

A central topic of leadership research is the influence of leadership style, the attitude patterns held by leaders, and the behaviors they exhibit $[1,2]$. A leader's leadership consists of a series of elements, including both environmental factors and personal factors. The environmental factors include the working conditions and team atmosphere, while the personal factors reflect the leader's own ability. At the same time, because of the differences in these factors, leaders are divided into different types. In China, for example, leaders are often divided into the traditional paternalistic leader and transformational leader [3]. The traditional paternalistic leadership includes the following three types: servant leader, ethical leader, and authentic leader [4]. In order to better understand the leadership level of different types of leaders, Judge [5] studied the relationship between transformational, transactional, and passive avoidance leadership and leadership effectiveness. Sheraz [6] explored the relationships between ethical leadership and transformational, transactional leadership, and organizational citizenship behavior. However, with the deepening of research, many scholars combine leadership with 
complexity. Among them, Olalere [7] found through research that using the complex leadership model enables leaders to better understand the complex leadership crisis.

In addition to the classification of different types of leaders, in recent years, many scholars have conducted systematic studies on the specific implementation of leadership. On the basis of summarizing relevant leadership literature, Morgeson et al. [8] focused on the leadership process within the team and described how team leadership was generated from four different sources inside and outside the team, so as to finally achieve the purpose of guiding and regulating leader behavior. Oc [9] comprehensively described the leadership situation by referring to Johns' category framework and systematically reviewed the existing theoretical framework and empirical results of background influence. Derue et al. [10] solved the problem of integrating research contents in related fields by establishing an integrated trait behavior model of leadership effectiveness and tested the relative validity of leadership traits and behaviors. Yukl [11] discusses the limitations and potential extensions of hierarchical taxonomies and proposes research proposals for improving effective leadership behavior.

Complexity is an important feature of the leadership system [12]. In recent years, scholars have gradually introduced complexity theory $[13,14]$ into leadership science, studying the structural complexity, process complexity, and application of leadership systems from different perspectives. Hernandez et al. [15] pointed out that the leadership system consists of leader, context, followers, collectives, and dyads five dimensions from the perspective of leadership status. Li and Mao [16] believed that the main elements of the leadership system are leader, subordinate, leader-subordinate interaction, and environment. Hooijberg et al. [17] reviewed the research in the field of cognitive, social, and behavioral complexity and proposed the Leaderplex Model. Uhl-Bien and Marion [18] studied the complexity of leadership in the form of bureaucratic organization and constructed a mesomodel of the theory of complexity leadership that includes administrative leadership, enabling leadership, and adaptive leadership. Hannah et al. [19] believed that leadership complexity is composed of static complexity and dynamic complexity. Static complexity is composed of the heterogeneity of groups or teams in the cognitive, social, self, and emotional fields.

The relationship between leaders and subordinates is always in a dynamic game process [20], which needs to consider the complex game situation in the short term [21], medium term [22], and long term [23]. Lord Xu and $\mathrm{Ma}$ [24] pointed out that leadership complexity includes both static and dynamic aspects. Static complexity involves general, social, ego, and emotional complexity. Based on the development law and endogenous logic in the real situation, dynamic complexity is created through the interaction of psychological processes new complex aspects. Uhl-Bien et al. [25] pointed out that the theory of complexity leadership is a leadership framework that enables the learning, creativity, and adaptability of the complex adaptive system (CAS) in knowledge production organizations. It includes three entangled leadership roles: adaptive leadership, administrative leadership, and enabling leadership. Uhl-Bien et al. [26] further pointed out that, in a complex adaptive system that transforms from old order to new order, entrepreneurial leadership produces innovation and growth; operational leadership transforms innovation into new adaptations; sexual order improves performance and results; and empowering leadership can open up adaptive spaces to ensure the continued viability and adaptability of the organization. Lichtenstein et al. [27] formally proposed the complexity leadership theory, thinking that leadership is an emergency and a result of interaction between components. Hogue and Lord [28] used complexity theory to incorporate existing gender bias explanations into a comprehensive model of leadership gender bias, which is used to understand how gender bias occurs throughout the leadership process and affects women.

In addition, leaders often carry out activities in a dynamic system in real life [29], so it is very important to combine leadership with a dynamic system [30]. Schneider and Somers [31] examined the leadership process in complex adaptive systems. They concluded that leaders indirectly influenced the organization through the intermediary variables of organizational identity and social movement and proposed to use dynamic system simulation and artificial neural networks as further development and testing of complex adaptive systems. Osborn and Hunt [32] criticized the idea that organizations were on the verge of chaos in complex adaptive systems and would exhibit "free order" behavior. They regarded organizations as a hierarchical structure may be guided by a collective to build a bottom-up structure to improve the organization's longterm effective power system. Wolfgramm et al. [33] constructed a sustainable interaction dynamic interaction (DIAL) model and analyzed the dynamic interaction process among the four sustainable leadership components of habit, imagination, learning, and judgment. Baltaci and Balci [34] defined complex leadership as an adaptive mechanism developed by complex organizations under the new conditions required by the information age, which is specifically composed of executive leadership, adaptive leadership, and action-centered leadership. Cardiff et al. [35] believed that human-centered leadership was a complex, dynamic, relational, and background practice aimed at enabling leaders and employees to achieve selfrealization, empowerment, and well-being. Plsek and Wilson [36] found that treating an organization as a complex and adaptive system can form a new and more effective management method in the healthcare organization. Those who seek to change the organization should harness such principles as generative relationships, minimum specification, the positive use of attractors for change.

Based on the above research, the current research on the emerging leadership theory of complexity leadership is still at the exploratory stage. In terms of research methods, there are many qualitative studies and a few quantitative studies. No one has yet adopted chaos theory and dynamic system simulation to analyze the dynamics of the leadership system complexity; no one has comprehensively studied the 
complex interactions and specific internal mechanisms between leadership, followership, Leader-Member Exchange (LMX), leadership situation, and leadership effectiveness based on the CAS perspective and put forward targeted application suggestions. Therefore, it is time to solve the problem of developing and testing a full-factor leadership model based on the complex theory proposed by Schneider and Somers [31] and other scholars.

Therefore, based on the current research progress of leadership, combined with chaos theory and complex dynamic system simulation, this paper established a dynamic model of relational leadership system with pressure factors, to further analyze the interactive relationship and internal mechanism in the leadership system and put forward effective suggestions to help leaders improve leadership effectiveness.

\section{The Model}

2.1. Model Building. Based on previous research results, we believe that the relationship leadership system consists of leaders, followers, Leader-Member Exchange (LMX), leadership situations, and leadership effectiveness. A relationship leadership dynamic system diagram is shown in Figure 1. Leadership and followership are the most dynamic elements in the relational leadership dynamic system; this paper selects leadership and followership as the main influencing factors among multiple factors which affect leadership effectiveness and analyzes the influencing process in the leadership situation. The leadership situation is determined by three independent variables : favor, social circle, reputation; the leadership includes four independent variables: cognitive ability, cohesion, moral quality, and achievement motivation; and the followership includes five independent variables: aggressive spirit, cognitive perception, executive skills, influence, and relationships. According to the relational leadership theory proposed by Uhl-Bien [37], leadership is subdivided into self-leadership (including achievement motivation and moral quality) and relational leadership (including cognitive ability and cohesion) from the entity perspective and the relationship perspective. Among them, self-leadership highlights the individual orientation of the leader's achievement motivation and moral quality while relational leadership highlights relational orientation of the leader's subject-object cognitive relationship and the LMX relationship between the leader and the follower. This paper aims at providing a basis for leadership decisions by establishing a relational leadership dynamic system model, analyzing the complex dynamic behavior between leadership effectiveness and influencing factors, and then performing numerical simulation through MATLAB and Mathematica, using bifurcation graphs and exponential graphs to analyze the complex dynamic characteristics of the relational leadership dynamic system.

2.2. Variable Setting (Interaction). In the following sectors, we are going to investigate the relationship between leadership effectiveness and influencing factors, and accurately establish the mathematical model of the relational leadership dynamic system. Before modeling, first, some reasonable assumptions for each variable are listed here:

(1) During a specific leadership period, the LeaderMember Exchange (LMX) is relatively unchanged

(2) Leaders and followers take limited rational decisions

(3) Self-leadership and relational leadership can be adjusted through education and training

Above these assumptions, the relationship $\mathrm{R}$ is used as an implicit variable rather than an independent variable when constructing a mathematical model. It is an important foothold for studying the relationship leadership system. One can propose effective and practical leadership strategies by studying the relationship between leadership effectiveness and its influencing factors to improve leadership performance. As mentioned earlier, it needs to establish a mathematical model of the relational leadership dynamic system. According to the characteristics and actual situation of the relationship dynamic system, the leadership situation, leadership, and followership include multiple subvariables. The relationship is as follows.

According to the characteristics of the relational leadership dynamic system, let the leadership situation be $S$ (including three subvariables of human feelings, circles, and face); let the leadership be $L$ (including four subvariables of cognitive ability, achievement motivation, cohesion, and moral quality), and let followership be $F$ (including five subvariables of influence, cognitive perception, relationship skills, enterprising spirit, and executive skills); let leadership effectiveness be $P$ (the result of the combined effects of $L, F$, and $S$ ).

We build a mathematical model of multifactor driven relational leadership dynamic system, in which $m$ represents the leader's self-leadership coefficient, $d$ represents the relational leadership coefficient, and $E_{1}, E_{2}, E_{3}, E_{4}$ all have negative effects.

The variables and parameters to be used in this paper are listed in Table 1.

The detailed relational expressions of the above variables are given below.

Cognitive ability and cohesion are affected by the relational leadership coefficient $d$, achievement motivation is affected by the self-leadership coefficient $m$, and moral is essential in the category of self-leadership, but according to moral leadership theory, moral leadership has an important relationship with followers, so the moral factor is influenced by both the relational leadership coefficient $d$ and the selfleadership coefficient $m$ :

$$
L=a_{1}+L_{1} d+L_{2} m+L_{3} d+L_{4}(m+d)-E_{1} .
$$

Equation (1) indicates that a leader's leadership is influenced by various internal factors. Among them, the cognitive ability and cohesion are mainly affected by the relationship coefficient of leadership and realize the achievement motivation is affected by the leader's selfleadership coefficient, while morals by internal and external two factors work together, so a leader in cognitive ability, 


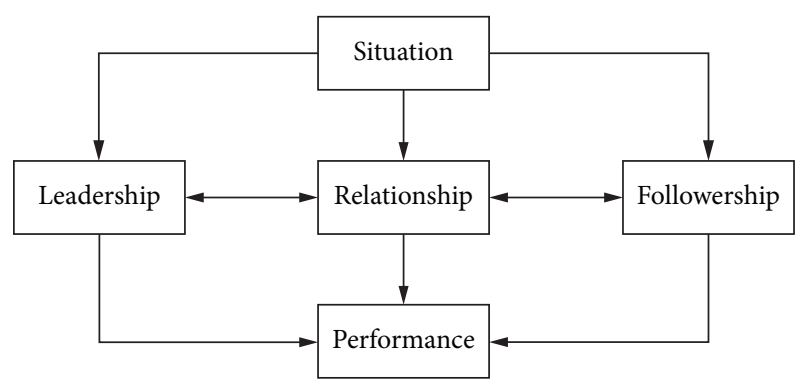

FIGURE 1: Multifactor relational leadership dynamic system model diagram.

TABLE 1: The notations used in this work.

\begin{tabular}{lc}
\hline Notation & Explanation \\
\hline$S$ & Leadership situation \\
$S_{1}$ & Human feelings \\
$S_{2}$ & Circles \\
$S_{3}$ & Face \\
$L$ & Leadership \\
$L_{1}$ & Cognitive ability \\
$L_{2}$ & Achievement motivation \\
$L_{3}$ & Cohesion \\
$L_{4}$ & Moral quality \\
$F$ & Followership \\
$F_{1}$ & Influence \\
$F_{2}$ & Cognitive perception \\
$F_{3}$ & Relationship skills \\
$F_{4}$ & Enterprising spirit \\
$F_{5}$ & Executive skills \\
$P$ & Leadership effectiveness \\
$m$ & The leader's self-leadership coefficient \\
$d$ & The relational leadership coefficient \\
$E_{i}(i=1,2,3,4)$ & Negative effect \\
$a_{i}(i=1,2,3,4)$ & Constant term \\
$\alpha$ & The coefficient of base effectiveness \\
$\varepsilon$ & Stressful coefficient \\
$B$ & The limiting value of stress \\
$\beta$ & The coefficient of mood swings \\
\hline
\end{tabular}

and the stronger the cohesion of the team, the greater the motivation of self-value realization, and the higher the level of morality, the stronger its leadership.

According to the results of existing research, leadership has an impact on followership through LMX, and leadership has an impact on leadership situations. Therefore, the leader's self-leadership coefficient $m$ and the relational leader coefficient $d$ will both affect the followership and leadership situation accordingly. At the same time, basic leadership effectiveness is influenced by leadership, followership, and leadership situations:

$$
\begin{aligned}
& F=a_{2}+F_{1}(m+d)+F_{2} d+F_{3} d+F_{4} m+F_{5} m-E_{2}, \\
& S=a_{3}+S_{1} m+S_{2}(m+d)+S_{3} m-E_{3},
\end{aligned}
$$

$$
\begin{aligned}
P_{b} & =a_{4}+d_{1} L+d_{2} F+d_{3} S-E_{4}, \\
\text { where } d_{1} & =d, d_{2}=m, d_{3}=(m+d) .
\end{aligned}
$$

Similar to equation (1), equations (2)-(3) refer to the following ability and the influence of the leadership by its constituent elements, based on the different degrees of influence of internal and external environment on leaders. Take leadership as an example. Leadership is mainly affected by external factors such as the leader's face and affinity, so the leader's relationship leadership coefficient plays an important role in a number of factors. Equation (4) represents the main components of basic leadership effectiveness, including leadership, leadership situation, and followership.

The final leadership effectiveness of a leader not only includes basic leadership effectiveness but also is affected by certain spiritual elements. A leader produces a base level of effectiveness based on the effectiveness of his leadership. However, with the increase of the effectiveness of leaders, the working pressure of leaders will increase. When the pressure exceeds a certain value, it will have a negative impact due to emotional fluctuations. On the contrary, it will have a certain positive effect. Therefore, according to equations (2)-(4), the final leadership efficiency of leaders is shown as follows:

$$
P=\alpha P_{b}+\left(\varepsilon P_{b}-B\right) \beta
$$

By equation (5), we know the final leadership effectiveness is made up of two parts: one part is based on leadership effectiveness into part of the final performance and the other part is the ultimate performance of the pressure of leadership effectiveness transformation; namely, when a leader's leadership effectiveness is greater than the pressure line $B$, it will produce negative effects, and when its leadership effectiveness is less than the pressure line $B$, it will produce a positive effect.

\section{Model Solution}

To reflect the influence of a single parameter on leadership effectiveness, the self-leadership coefficient $m$ and the relational leadership coefficient $d$ are selected as important parameters. The partial derivative of the leadership effectiveness expression is obtained respectively to obtain the partial derivative equations of the two parameters and draw a graph of the influence of self-leadership coefficient $m$ and relational leader coefficient $d$ on leadership effectiveness in a single event. The partial derivatives of $m$ and $d$ for leadership effectiveness are shown as follows: 
$\frac{\partial P}{\partial m}=\left(\begin{array}{c}a_{2}-E_{3}-E_{2}+a_{3}+F_{2} d+F_{3} d+d\left(L_{2}+L_{4}\right)+ \\ F_{4} m+F_{5} m+\left(F_{1}+F_{4}+F_{5}\right) m+F_{1}(d+m)+ \\ m S_{1}+S_{2}(d+m)+m S_{3}+\left(S_{1}+S_{2}+S_{3}\right)(d+m)\end{array}\right)(\alpha+\beta \varepsilon)$,

$\frac{\partial P}{\partial d}=\left(\begin{array}{c}a_{1}-E_{3}-E_{1}+a_{3}+L_{1} d+L_{3} d+d\left(L_{1}+L_{3}+L_{4}\right)+ \\ m\left(F_{1}+F_{2}+F_{3}\right)+m L_{2}+L_{4}(d+m)+m S_{1}+ \\ m S_{3}+2(d+m) S_{2}\end{array}\right)(\alpha+\beta \varepsilon)$.

Noticed that the second-order partial derivative $\partial 2 \mathrm{P} / \partial \mathrm{m}_{2}$ $=2 \mathrm{a}\left(\mathrm{F}_{1}+\mathrm{F}_{5}+\mathrm{S}_{1}+\mathrm{S}_{2}+\mathrm{S}_{3}\right)>0, \partial_{2} \mathrm{P} / \partial \mathrm{d}_{2}={ }_{2} \alpha\left(\mathrm{L}_{1}+\mathrm{L}_{3}+\mathrm{L}_{4}+\right.$ $\left.\mathrm{S}_{2}\right)>0$, the equation has a maximum. Through partial derivation of $\mathrm{m}$ and $\mathrm{d}$ for leadership effectiveness $\mathrm{P}$, and let $\partial P / \partial m=0, \partial P / \partial d=0$, we can obtain the optimal value of self-leadership coefficient $\mathrm{m}^{*}$ and relationship leadership coefficient $\mathrm{d}^{*}$ in the leadership context, full details are given in Appendix.

Based on equations (6) and (7), we have the following proposition.

Proposition 1. In the leadership effectiveness system, the gradient value of self-leadership coefficient $m$ and relationship leadership coefficient $d$ is independent of the limiting value of stress $B$ and linearly related to $\alpha, \varepsilon$, and $\beta$.

Proposition 2. The optimal value of self-leadership coefficient $m$ and relationship leadership coefficient $d$ is independent of $\alpha, \varepsilon$, and $\beta$. It is only related to the constituent elements in leadership situation $S$, leadership $L$, and followership F.

In a single cycle, the leaders are faced with a lot of affairs, and it is not possible to explore what kind of leadership the leader should adopt from the analysis of a single transaction. This paper believes that leaders will make changes to the next leadership style based on the impact of the previous leadership style on leadership effectiveness. Here, the method of limited rational analysis is introduced. We assume that the leader does not fully understand the leadership effectiveness $P$ and cannot analyze the change of the leadership effectiveness $P$ from an objective perspective, which means the leader's judgment on the leadership effectiveness $P$ has certain limitations. According to the multifactors driven relational leadership dynamic system, we establish the following Markov chain model. $g_{i}(i=1,2)$ represents the selfleadership adjustment factor, the specific model is as follows:

$$
\left\{\begin{array}{l}
m(t+1)=m(t)+g_{1} m(t) \frac{\partial P(t)}{\partial m(t)}, \\
d(t+1)=d(t)+g_{2} d(t) \frac{\partial P(t)}{\partial d(t)} .
\end{array}\right.
$$

By the previous equation, we know, in the period $t$, when leaders of the marginal leader's self-leadership coefficient and the marginal relational leadership coefficient are greater than 0 , the leader will continue the current decision in the period $t+1$, and when leaders of the marginal leader's selfleadership coefficient and the marginal relational leadership coefficient are less than 0 , the leader will change its decision in the next period.

\section{Numerical Simulation}

4.1. Static Simulation. To explore the influence of selfleadership coefficient $m$ and relational leadership coefficient $d$ on leadership effectiveness, we conduct a numerical simulation of the system:

$$
\begin{aligned}
a_{1} & =2.47 ; \\
a_{2} & =0.5 ; \\
a_{3} & =0.5 ; \\
a_{4} & =0.5 ; \\
E_{1} & =0.2 ; \\
E_{2} & =0.2 ; \\
E_{3} & =0.12 ; \\
E_{4} & =0.12 ; \\
F_{1} & =0.1 ; \\
F_{2} & =0.6 ; \\
F_{3} & =0.8 ; \\
F_{4} & =0.8 ; \\
F_{5} & =0.3 ; \\
S_{1} & =0.295 ; \\
S_{2} & =-1.43 ; \\
S_{3} & =0.02 ; \\
L_{1} & =0.15 ; \\
L_{2} & =0.2 ; \\
L_{3} & =0.2 ; \\
L_{4} & =0.2 ; \\
\alpha & =0.7 ; \\
\varepsilon & =0.5 ; \\
B & =0.3 ; \\
\beta & =0.3
\end{aligned}
$$

We plot the effects of self-leadership coefficient $m$ and relational leader coefficient $d$ on leadership effectiveness in a single event. The specific simulation results are shown in Figure 2.

As can be seen from Figure 2, with the increase of selfleadership coefficient $m$, the leadership effectiveness continues to decrease, which means that a single-handed leader will do harm to the whole organization. However, with the increase of self-leadership coefficient $m$, the decline rate of leadership effectiveness $P$ gradually slows down.

Next, we will conduct relevant research on the relationship between the relationship leadership coefficient $d$ and leadership effectiveness $P$, as shown in Figure 3.

Figure 3 shows that, with the increase of the relationship leadership coefficient $d$, the leadership effectiveness will increase. When $d$ is approximately equal to 0.9 , the 


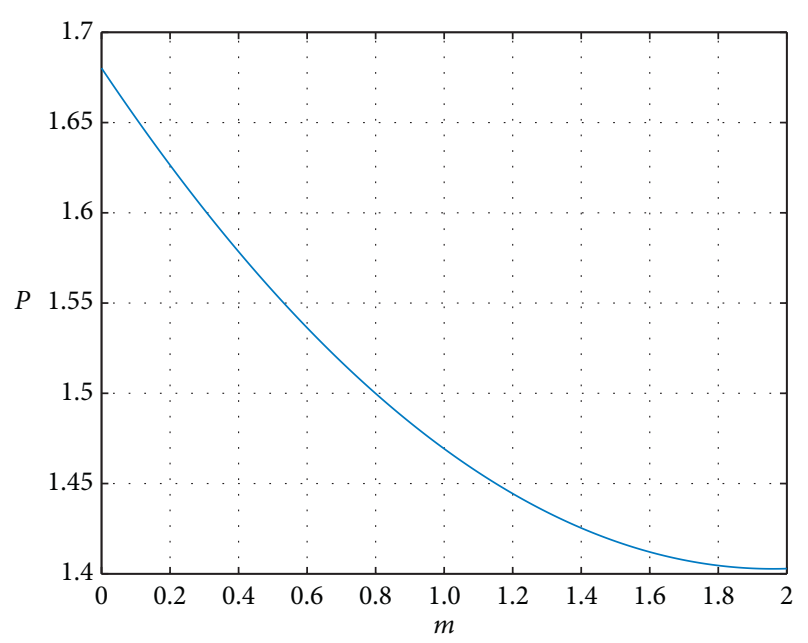

Figure 2: Relationship between self-leadership coefficient $m$ and leadership effectiveness $P$.

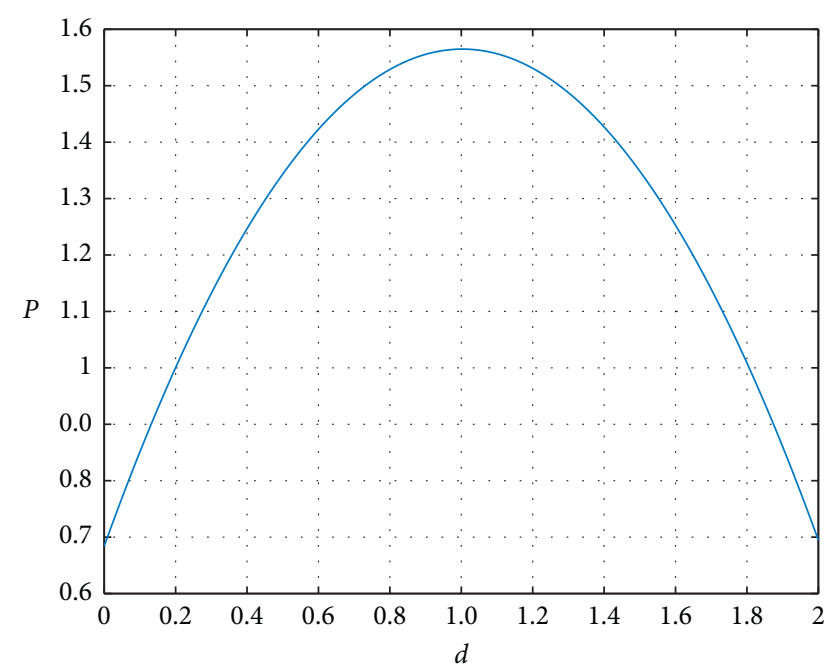

FIGURE 3: Relationship between the relationship leadership coefficient $d$ and leadership effectiveness $P$.

leadership effectiveness peaks, but when $d$ is greater than 1 , the leadership effectiveness will gradually decrease. That is, when the relational leadership coefficient is large to a certain extent, leadership effectiveness no longer rises, but declines. This result is also consistent with the actual situation.

Figures 2 and 3 show the influence of changes in the selfleadership coefficient $m$ and the relationship leadership coefficient $d$ on leadership effectiveness. Next, we study the leadership effectiveness $P$ when the self-leadership coefficient $m$ and the relational leadership coefficient $d$ change simultaneously. Here, we set the range of the self-leadership coefficient $m$ and the relational leader coefficient $d$ from -2 to 5 , which allows us to observe the changes brought by these two parameters more intuitively.

Then, we will show the relationship between self-leadership coefficient $m$ and relational leadership coefficient $d$ and leadership effectiveness $P$ more intuitively, as shown in Figure 4.

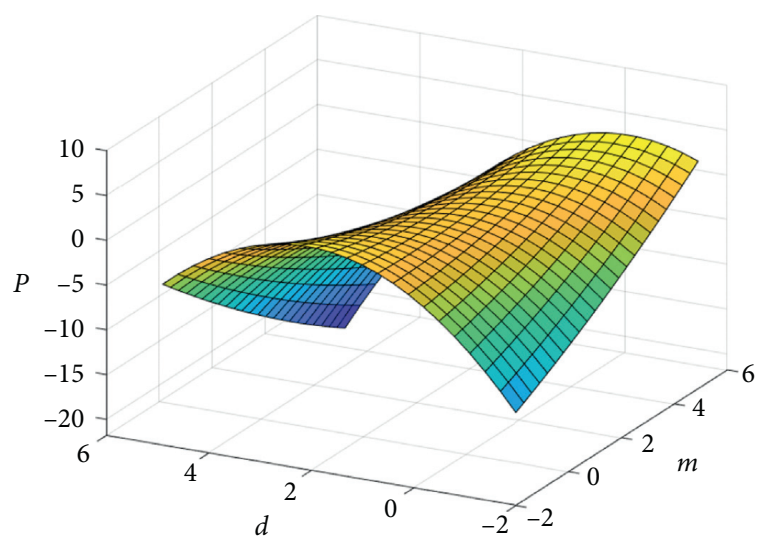

FIgURE 4: Relationship between self-leadership coefficient $m$ and relational leadership coefficient $d$ and leadership effectiveness $P$.

As shown in the three-dimensional picture of Figure 4, we can intuitively observe the influence of the self-leadership coefficient $m$ and the relational leadership coefficient $d$ on leadership effectiveness. From Figure 4, we can see that, with the constant increase of the self-leadership coefficient $m$ and the relational leadership coefficient $d$, the leader's leadership effectiveness first increases and then decreases. When parameter $m$ and parameter $d$ are both too high or too low, the leadership effectiveness of the leader is the lowest. When $m=4.9, d=-0.5$, there is the highest leadership effectiveness.

4.2. Dynamic Simulation. Leaders usually change their selfleadership coefficients and relational leadership coefficients according to the changes of leadership effectiveness. Next, this study analyzes the complex characteristics of selfleadership coefficient $m$, relational leadership coefficient $d$, and leadership effectiveness $P$ by drawing bifurcation diagrams and LLE diagrams, as shown in Figures 5-8.

From Figure 5, we can see that the change of self-leadership adjustment coefficient $g_{1}$ affects the leader's self-leadership coefficient and relational leadership coefficient. In the overall complex dynamic system, when the self-leadership adjustment coefficient $g_{1}=0.16$, the system goes into an unstable state. With the increase of the self-leadership adjustment coefficient, when $g_{1}=0.21$, the values of $m$ and $d$ gradually enter into a chaotic state.

From Figure 6, we can see that, as the leader's selfleadership adjustment system increases, leadership effectiveness first rises rapidly, then enters a stable state, and finally enters a chaotic state. Similar to Figure 5, when $g_{1}<0.21$, the leadership effectiveness will be stable at 1.53 , and the leadership effectiveness has been rapidly increasing until then. However, after entering an unstable state, the leadership effectiveness is often higher than that in a steadystate.

Figure 7 is similar to Figure 5, we can see that the change of self-leadership adjustment coefficient $g_{2}$ affects the leader's self-leadership coefficient and relational leadership coefficient. We find that when $g_{2}=1.07$, the system enters a bifurcation. When $g_{2}=1.1$, the system bifurcates again and enters chaos. Compared with the 


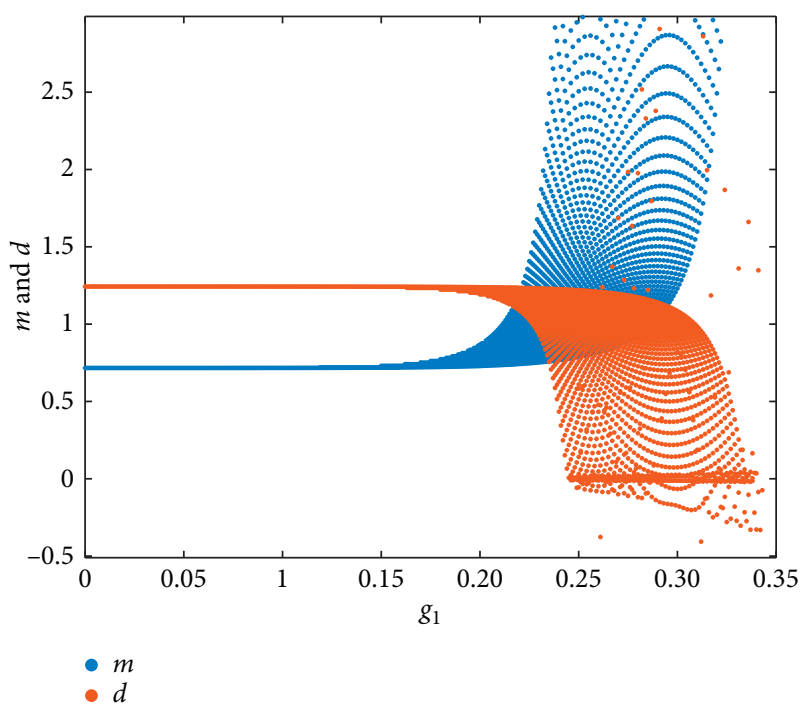

Figure 5: The effect of the adjustment coefficient on the leadership self-leadership coefficient and relational leadership coefficient.

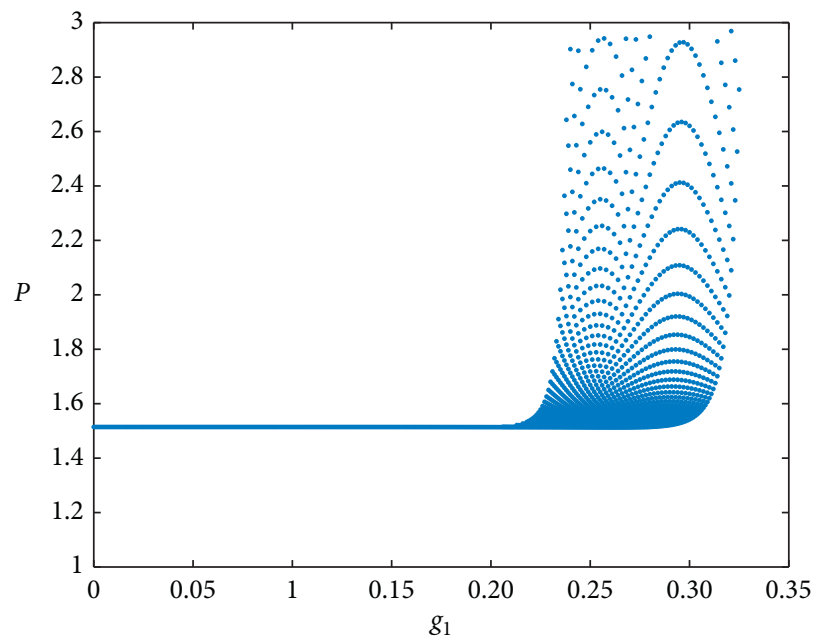

FIGURE 6: The effect of adjustment factors on leadership effectiveness.

self-leadership adjustment coefficient $g_{1}$, under the premise of stable leadership effectiveness, the self-leadership adjustment coefficient $g_{2}$ has a large adjustment interval and enters an unstable state faster. The adjustment interval of coefficient $m$ and coefficient $d$ from an unstable state to chaotic state is very small.

Similar to Figure 6, we can see from Figure 8 that, as the leader's self-leadership adjustment coefficient increases, the leadership effectiveness also rises quickly, then enters a stable state, and finally enters a chaotic state. When $g_{2}<1.07$, the leader's leadership effectiveness stabilizes at 1.53 , which is the same as the adjusted steady-state value of $g_{1}$. Similar to Figure 7 , when $g_{2}=1.07$, the leadership effectiveness diverges and enters an unstable state. When $g_{2}=1.1$, the system bifurcates again and enters chaos. Under unstable conditions, compared with the leadership effectiveness adjusted by $g_{1}$, the leadership effectiveness adjusted by $g_{2}$ is lower than the stable leadership effectiveness.

\section{Chaos Control}

From the conclusions obtained in the previous section, it has been realized that when the self-leadership adjustment coefficient is too high, the self-leadership coefficient and relational leadership coefficient will enter an unstable state, and eventually chaos will appear. If leaders fail to make correct decisions to adjust their leadership, leadership effectiveness will also be affected and fluctuations will occur, which ultimately leads to poor leadership performance. Considering the influence of the chaos on leaders, it is necessary for leaders to effectively control chaos to ensure the correct decision-making of the leadership, so as to stabilize the leadership effectiveness and benefit the system. According to the characteristics of the entire decisionmaking process, this study adjusts the decision-making method to control chaos, so the delay control method is considered. The core idea of the delay control method is to feedback the system after the system delays. In other words, this study observes that some of the information is the 


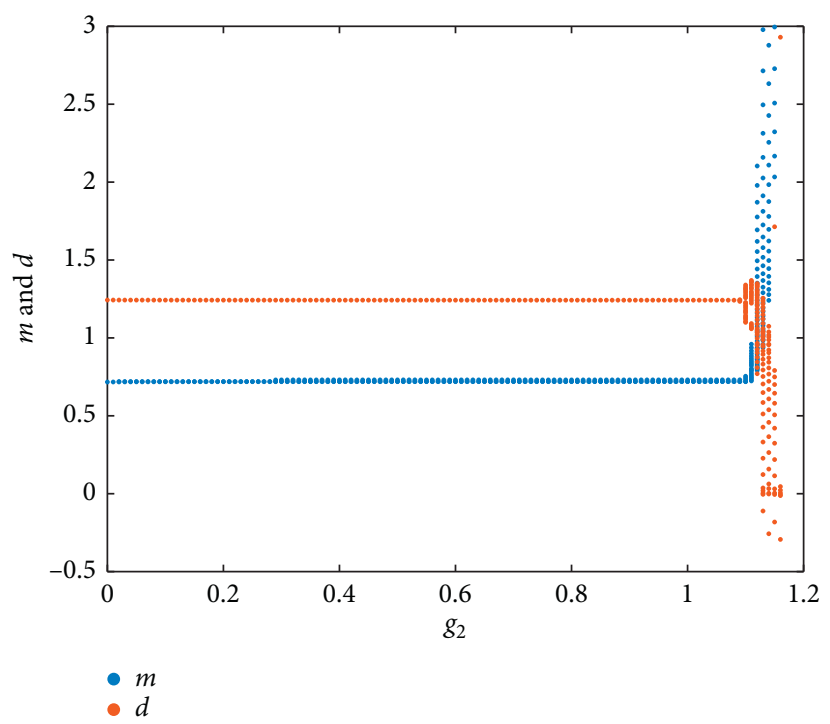

Figure 7: The effect of the adjustment coefficient on the leadership self-leadership coefficient and relational leadership coefficient.

output signal of the system. When deciding the next cycle, we consider the decision in period $t$. Therefore, the dynamic adjustment model is as follows:

$$
\left\{\begin{array}{l}
m(t+1)=m(t)+g_{1} m(t) \frac{\partial P(t)}{\partial m(t)}+g(m(t)-m(t+1)), \\
d(t+1)=d(t)+g_{2} d(t) \frac{\partial P(t)}{\partial d(t)}+g(d(t)-d(t+1)) .
\end{array}\right.
$$

We set the parameters as

$$
\begin{aligned}
& a_{1}=2.47 ; \\
& a_{2}=0.5 ; \\
& a_{3}=0.5 ; \\
& a_{4}=0.5 ; \\
& E_{1}=0.2 ; \\
& E_{2}=0.2 ; \\
& E_{3}=0.12 ; \\
& E_{4}=0.12 ; \\
& F_{1}=0.1 ; \\
& F_{2}=0.6 ; \\
& F_{3}=0.8 ; \\
& F_{4}=0.8 ; \\
& F_{5}=0.3 ; \\
& S_{1}=0.295 ; \\
& S_{2}=-1.43 ; \\
& S_{3}=0.02 ; \\
& L_{1}=0.15 ; \\
& L_{2}=0.2 ; \\
& L_{3}=0.2 ; \\
& L_{4}=0.2 .
\end{aligned}
$$

Since the adjustment parameters of each decision variable in the system are different when entering chaos, we set different adjustment parameters for different decision variables here. For variables $d, p$, and $m$, we set the adjustment parameters as follows: $g_{1}=0.28, g_{2}=0.35$. In this case, the original system is in a chaotic state. This study introduces control parameters $g$ and adds delayed feedback to the decision signal. Through numerical simulation, we draw a bifurcation diagram with increasing control parameters $g$, as shown in Figure 9.

From Figure 9, we can see that adding delayed feedback to the leadership decision eliminates the instability of the system effectively. When $g$ is very small, the system is chaotic. With the increase of the control parameter $g$, the leaders' self-leadership coefficients and relational leadership coefficients of the system gradually stabilize. When $g>0.3$, the leadership effectiveness also changes with the change of the two coefficients and finally breaks away from the chaotic state and reaches a stable state. At that time, the entire system remains stable and leaders could make effective decisions.

In Figures 5-8, with the increase of adjustment parameters, the leaders' self-leadership coefficients, relational leadership coefficients, and leadership effectiveness gradually enter into a chaotic state. However, in Figure 9, the chaotic state is controlled with the increase of control parameters and finally returns to a stable state, which also shows that the delay strategy can prevent the excessive adjustment of the leaders' self-leadership coefficients and relational leadership coefficients by leaders, prevent the instability of leadership effectiveness, and enhance the stability of the enterprise. It also can be concluded that delaying control based on the leader's self-leadership and relational leadership is a good method of controlling the system. 


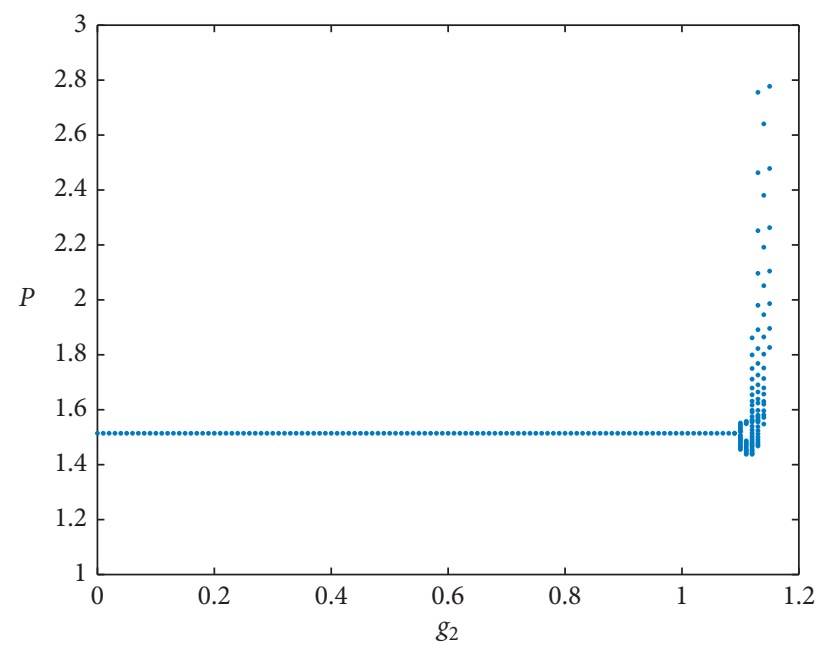

FIGURE 8: Influence of self-leadership adjustment coefficient on leadership effectiveness.

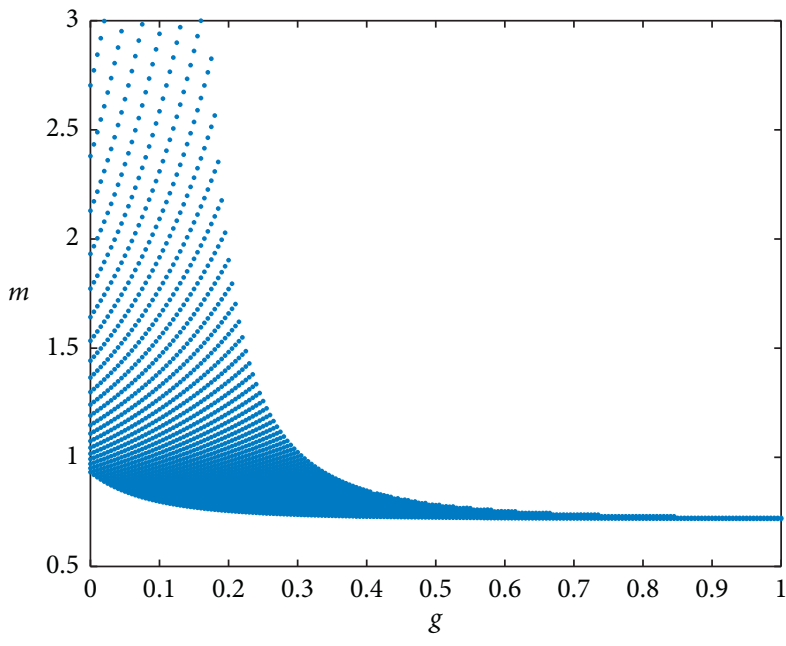

(a)

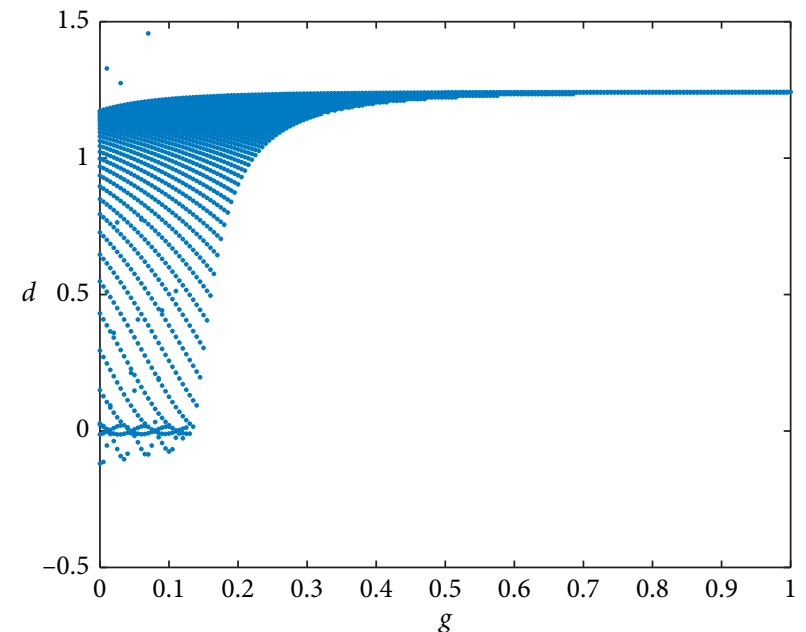

(b)

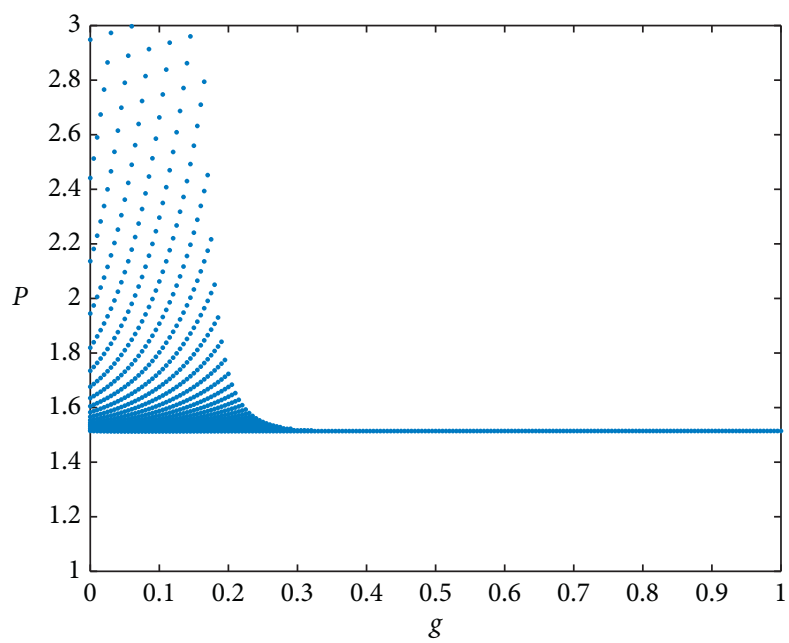

(c)

FIGURE 9: Bifurcation diagram when $g$ increasing. (a) Self-leadership coefficient $m$. (b) Relational leadership coefficient $d$, and (c) Leadership effectiveness $p$. 


\section{Conclusion}

This paper studies the influence of leaders' self-leadership coefficient and relational leadership coefficient on the leadership effectiveness in single-cycle and multicycle leadership situations, to analyze how leaders should make decisions in business decision-making. First of all, this paper constructs the final leadership effectiveness model by analyzing the components of leadership that influence leaders' decisions and combining spiritual factors. Then, the influence of parameters in static and dynamic systems is analyzed by numerical simulation. Through research, we reach the following conclusions:

(1) When the self-leadership coefficient $m$ increases, the leadership effectiveness will gradually decrease, but the reduced gradient will decrease. This shows that the mere increase of self-leadership is not conducive to the improvement of leaders' leadership. When self-leadership reaches a certain height, leadership will no longer decrease.

(2) Similarly, with the relationship leadership coefficient $d$, the leader's leadership first increases and then decreases. This indicates that relatively small relational leadership is conducive to leaders' decisionmaking, but too much emphasis on relational leadership will have adverse effects on leadership.

(3) Leaders use limited rational expectations to make changes in the leadership effectiveness in business decision-making to show that leaders use limited rational decision-making strategies in multicycle decision-making so that leaders can maintain high leadership effectiveness in decision-making. At the same time, when making adjustments to bounded rational decision-making, the system needs to be in a stable state. Once it enters a chaotic state, the leader's decision will appear in a chaotic state that cannot predict the optimal decision. And this should be avoided.

(4) The delay control can control the unstable and chaotic state of leadership in the dynamic system and make it gradually enter the stable state. This also shows that the combination of predicted leadership and current leadership is conducive to the leader's decision-making to keep the enterprise or market stable.

This paper takes into account various leadership components and spiritual factors, which has certain reference value in the field of leadership research. But the purpose of this article is to describe a comprehensive leader. In real life, there are many types of leaders in an enterprise, and different leaders have limited leadership competition. Future research should focus on the study of leaders of all types.

\section{Appendix}

$$
\begin{aligned}
& m^{*}=\frac{\left(\begin{array}{c}
E_{1} F_{1}+E_{3} F_{1}+E_{1} F_{2}+E_{3} F_{2}+E_{1} F_{3}+E_{3} F_{3}+2 a_{2} L_{1}-2 E_{2} L_{1}-2 E_{3} L_{1}+E_{1} L_{2}+E_{3} L_{2}+2 a_{2} L_{3} \\
-2 E_{2} L_{3}-2 E_{3} L_{3}+2 a_{2} L_{4}+E_{1} L_{4}-2 E_{2} L_{4}-E_{3} L_{4}+E_{1} S_{1}+E_{3} S_{1}+2 a_{2} S_{2}+2 E_{1} S_{2}-2 E_{2} S_{2} \\
+E_{1} S_{3}+E_{3} S_{3}-a_{3}\left(F_{1}+F_{2}+F_{3}-2 L_{1}+L_{2}-2 L_{3}-L_{4}+S_{1}+S_{3}\right)- \\
a_{1}\left(F_{1}+F_{2}+F_{3}+L_{2}+L_{4}+S_{1}+2 S_{2}+S_{3}\right)
\end{array}\right)}{\left(\begin{array}{c}
F_{1}^{2}+F_{2}^{2}+F_{3}^{2}-4 F_{4} L_{1}-4 F_{5} L_{1}+2 F_{3} L_{2}+L_{2}^{2}-4 F_{4} L_{3}-4 F_{5} L_{3}+2 F_{3} L_{4}-4 F_{4} L_{4}-4 F_{5} L_{4}+ \\
2 L_{2} L_{4}+L_{4}^{2}+2 F_{3} S_{1}-4 L_{1} S_{1}+2 L_{2} S_{1}-4 L_{3} S_{1}-2 L_{4} S_{1}+S_{1}^{2}+4 F_{3} S_{2}-4 F_{4} S_{2}-4 F_{5} S_{2}- \\
4 L_{1} S_{2}+4 L_{2} S_{2}-4 L_{3} S_{2}+2 F_{3} S_{3}-4 L_{1} S_{3}+2 L_{2} S_{3}-4 L_{3} S_{3}-2 L_{4} S_{3}+2 S_{1} S_{3}+S_{3}^{2} \\
+2 F_{1}\left(F_{2}+F_{3}-2 L_{1}+L_{2}-2 L_{3}-L_{4}+S_{1}+S_{3}\right)+2 F_{2}\left(F_{3}+L_{2}+L_{4}+S_{1}+2 S_{2}+S_{3}\right)
\end{array}\right)}
\end{aligned}
$$

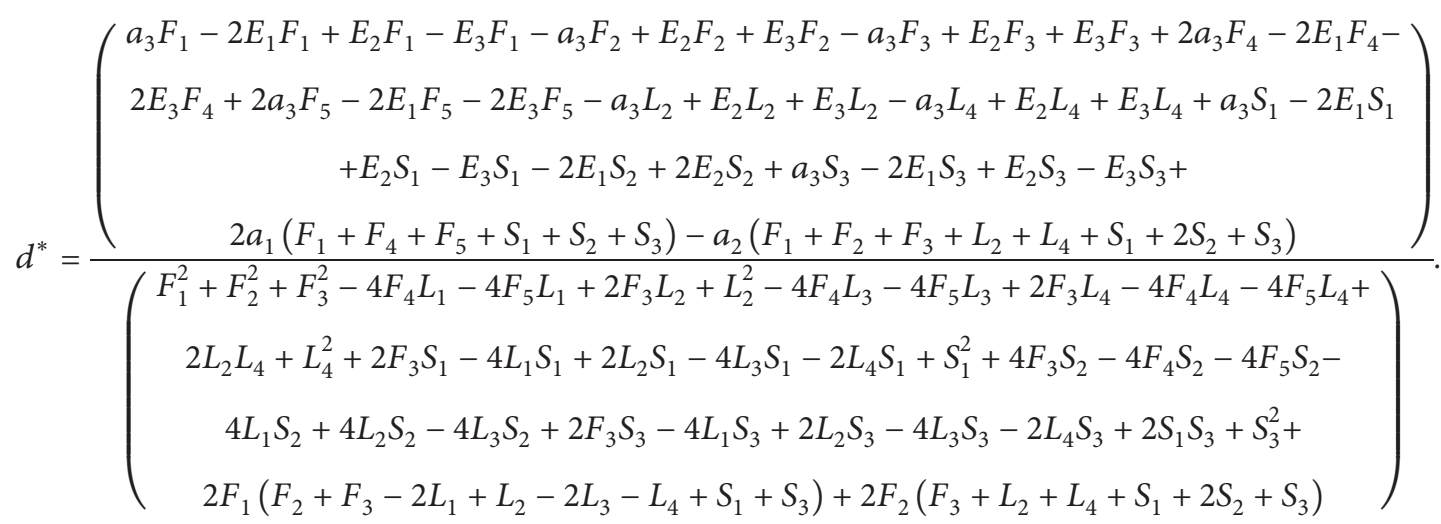




\section{Data Availability}

The data used to support the findings of this study are available from the corresponding author upon request. The questionnaire data were acquired mainly through e-mail and paper filling out.

\section{Conflicts of Interest}

The authors declare no conflicts of interest.

\section{Acknowledgments}

This research was supported by the Tianjin University Innovation Fund. And, the authors thank Dr. Zongxian Wang for his effective work.

\section{References}

[1] M. H. Anderson and P. Y. T. Sun, "Reviewing leadership styles: overlaps and the need for a new "full-range" theory," International Journal of Management Reviews, vol. 19, no. 1, pp. 76-96, 2017.

[2] R. P. Vecchio and M. Sussmann, "Preferences for forms of supervisory social influence," Journal of Organizational Behavior, vol. 10, no. 2, pp. 135-143, 1989.

[3] C. H. V. Lin and J. M. J. Sun, “Chinese employees' leadership preferences and the relationship with power distance orientation and core self-evaluation," Frontiers of Business Research in China, vol. 12, no. 1, p. 6, 2018.

[4] J. E. Hoch, W. H. Bommer, J. H. Dulebohn, and D. Wu, "Do ethical, authentic, and servant leadership explain variance above and beyond transformational leadership? A metaanalysis," Journal of Management, vol. 44, no. 2, pp. 501-529, 2018.

[5] T. A. Judge and R. F. Piccolo, "Transformational and transactional leadership: a meta-analytic test of their relative validity," Journal of Applied Psychology, vol. 89, no. 5, p. 755, 2004.

[6] A. Sheraz, M. Nadeem, and I. U. Rehman, "Modeling link between transformational, transactional leadership and organizational citizenship behavior by mediating ethical leadership," Actual Problems of Economics, no. 2, pp. 302-308, 2012.

[7] A. Olalere, "Complexity and leadership crisis in Africa," International Journal of Public Leadership, vol. 11, no. 3-4, pp. 180-191, 2015.

[8] F. P. Morgeson, D. S. DeRue, and E. P. Karam, "Leadership in teams: a functional approach to understanding leadership structures and processes," Journal of Management, vol. 36, no. 1, pp. 5-39, 2010.

[9] B. Oc, "Contextual leadership: a systematic review of how contextual factors shape leadership and its outcomes," The Leadership Quarterly, vol. 29, no. 1, pp. 218-235, 2018.

[10] D. S. Derue, J. D. Nahrgang, N. Wellman, and S. E. Humphrey, "Trait and behavioral theories of leadership: an integration and meta-analytic test of their relative validity," Personnel Psychology, vol. 64, no. 1, pp. 7-52, 2011.

[11] G. Yukl, "Effective leadership behavior: what we know and what questions need more attention," Academy of Management Perspectives, vol. 26, no. 4, pp. 66-85, 2012.
[12] L. Xie, J. Ma, and M. Goh, "Supply chain coordination in the presence of uncertain yield and demand," International Journal of Production Research, no. 1, pp. 1-17, 2020.

[13] J. Ma, Z. Guo, and Y. Hong, "Demand-supply dynamics in FMCG business: exploration of customers' herd behavior," Nonlinear Dynamics, vol. 98, no. 3, 2019.

[14] J. Ma, Y. Hou, Z. Wang, and W. Yang, "Pricing strategy and coordination of automobile manufacturers based on government intervention and carbon emission reduction," Energy Policy, vol. 148, Article ID 111919, 2021.

[15] M. Hernandez, M. B. Eberly, B. J. Avolio, and M. D. Johnson, "The loci and mechanisms of leadership: exploring a more comprehensive view of leadership theory," The Leadership Quarterly, vol. 22, no. 6, pp. 1165-1185, 2011.

[16] M. Li and J. Mao, "A theoretical review of leadership research," Journal of Shanghai University of Administration, no. 16, pp. 91-102, 2015.

[17] R. Hooijberg, J. G. Hunt, and G. E. Dodge, "Leadership complexity and development of the leaderplex model," Journal of Management, vol. 23, no. 3, pp. 375-408, 1997.

[18] M. Uhl-Bien and R. Marion, "Complexity leadership in bureaucratic forms of organizing: a meso model," The Leadership Quarterly, vol. 20, no. 4, pp. 631-650, 2009.

[19] S. T. Hannah, R. G. Lord, and C. L. Pearce, "Leadership and collective requisite complexity," Organizational Psychology Review, vol. 1, no. 3, pp. 215-238, 2011.

[20] J. Ma, Y. Li, and Z. Wang, "Analysis of pricing and service effort in dual-channel supply chains with showrooming effect," International Journal of Bifurcation and Chaos, vol. 30, no. 16, Article ID 2050241, 2020.

[21] J. Ma, Y. Hou, W. Yang et al., "A time-based pricing game in a competitive vehicle market regarding the intervention of carbon emission reduction," Energy Policy, no. 1, p. 142, 2020.

[22] L. Zhao, "Analysis and control of the complex dynamics of a multimarket cournot investment game with bounded rationality," Discrete Dynamics in Nature and Society, vol. 2016, Article ID 7342405, 10 pages, 2016.

[23] B. Bao, J. Ma, and M. Goh, "Short-and long-term repeated game behaviours of two parallel supply chains based on government subsidy in the vehicle market," International Journal of Production Research, vol. 58, no. 24, pp. 7507-7530, 2020.

[24] T. Lord Xu and J. Ma, "Feed-in tariff or tax-rebate regulation? Dynamic decision model for the solar photovoltaic supply chain," Applied Mathematical Modelling, vol. 89, pp. 1106$1123,2020$.

[25] M. Uhl-Bien, R. Marion, and B. McKelvey, "Complexity leadership theory: shifting leadership from the industrial age to the knowledge era," The Leadership Quarterly, vol. 18, no. 4, pp. 298-318, 2007.

[26] M. Uhl-Bien and M. Arena, "Complexity leadership," Organizational Dynamics, vol. 46, no. 1, pp. 9-20, 2017.

[27] B. B. Lichtenstein, M. Uhl-Bien, R. Marion et al., "Complexity leadership theory: an interactive perspective on leading in complex adaptive systems," $E$ : CO, vol. 8, no. 4, pp. 2-12, 2006.

[28] M. Hogue and R. G. Lord, "A multilevel, complexity theory approach to understanding gender bias in leadership," The Leadership Quarterly, vol. 18, no. 4, pp. 370-390, 2007.

[29] F. Wu and J. Ma, "Evolution dynamics of agricultural internet of things technology promotion and adoption in China," Discrete Dynamics in Nature and Society, vol. 2020, Article ID 1854193, 18 pages, 2020. 
[30] W. Chaoqun, P. Yulong, and G. Jingpeng, "Evolution game model of travel mode choice in metropolitan," Discrete Dynamics in Nature and Society, vol. 2015, Article ID 638972, 11 pages, 2015.

[31] M. Schneider and M. Somers, "Organizations as complex adaptive systems: implications of complexity theory for leadership research," The Leadership Quarterly, vol. 17, no. 4, pp. 351-365, 2006.

[32] R. N. Osborn and J. G. Hunt, "Leadership and the choice of order: complexity and hierarchical perspectives near the edge of chaos," The Leadership Quarterly, vol. 18, no. 4, pp. 319-340, 2007.

[33] R. Wolfgramm, S. Flynn-Coleman, D. Conroy et al., "Dynamic interactions of agency in leadership (DIAL): an integrative framework for analysing agency in sustainability leadership," Journal of Business Ethics, vol. 126, no. 4, pp. 649-662, 2015.

[34] A. Baltaci and A. Balc1, "Complexity leadership: a theorical perspective," International Journal of Educational Leadership and Management, vol. 5, no. 1, pp. 30-58, 2017.

[35] S. Cardiff, B. McCormack, and T. McCance, "Person-centred leadership: a relational approach to leadership derived through action research," Journal of Clinical Nursing, vol. 27, no. 15-16, pp. 3056-3069, 2018.

[36] P. E. Plsek and T. Wilson, "Complexity science: complexity, leadership, and management in healthcare organisations," BMJ, vol. 323, no. 7315, pp. 746-749, 2001.

[37] M. Uhl-Bien, "Relational leadership theory: exploring the social processes of leadership and organizing," The Leadership Quarterly, vol. 17, no. 6, pp. 654-676, 2006. 